Revista Araticum

Programa de Pós-graduação em Letras/Estudos Literários da Unimontes v.21, n.1, 2020. ISSN: 2179-6793

\title{
ANÁLISE DE DISCURSO E ENSINO DE LITERATURA BRASILEIRA COM SUJEITOS SURDOS ENTRE-LÍNGUAS: DIZERES SOBRE O RACISMO E SUJEITO NO BRASIL DO SÉCULO XIX E SUA INSISTÊNCIA NO XXI
}

\section{DISCOURSE ANALYSIS AND TEACHING OF BRAZILIAN LITERATURE WITH DEAF SUBJECTS BETWEEN LANGUAGES: ABOUT RACISM AND SUBJECT IN 19TH CENTURY BRAZILAND ITS INSISTENCE ON THE 21ST CENTURY}

https://doi.org/10.46551/2179679320200004

Lívia Letícia Belmiro Buscácio Instituto Nacional de Educação de Surdos - INES liviabuscacio@gmail.com iD lttps://orcid.org/0000-0002-4773-8825

RESUMO: Com base na Análise de discurso (PÊCHEUX, 2008, 2009, 2011; ORLANDI, 1984, 2002), relato procedimentos metodológicos de uma prática realizada na disciplina de literatura com aprendizes surdos no Ensino Médio do CAP-INES. Ao abordar o período considerado como Realismo/ Naturalismo no Brasil, trabalhamos com o discurso sobre o racismo na formação do Brasil-nação no século XIX e seus efeitos até hoje, analisando diferentes materiais, como $O$ mulato (1881), de Aluísio de Azevedo, a pintura $A$ redenção de Cam (1895), de Modesto Brocos; além de materiais de arquivo coletados em sites institucionais e redes sociais. $O$ trabalho resultou na assunção de um lugar de leitor pelos aprendizes surdos, possibilitando que gestos de leitura sobre a temática fossem relacionados ao próprio lugar de sujeito na experiência com o discurso.

PALAVRAS-CHAVE: Análise de discurso; Literatura; Educação; Surdo; LIBRAS.

ABSTRACT: Based on the Discourse analysis PÊCHEUX, 2008, 2009, 2011; ORLANDI, 1984, 2002), I report methodological procedures of a practice performed in the literature discipline with deaf learners in High school at the CAPINES. In addressing the Realism / Naturalism period in Brazil, we worked with the discourse about racism in the formation of Brazil-nation in the 19th century and its effects until today, analyzing different materials, such as $O$ mulato (1881), by Aluísio de Azevedo, painting The redemption of Cam (1895), by Modesto Brocos; in addition to archival materials collected on institutional websites and social networks. The work resulted in the deaf learners assuming a place as a reader, enabling reading gestures on the theme to be related to the subject's own place in the experience with the discourse.

KEYWORDS: Discourse analysis; Literature; Education; Deaf; LIBRAS. 


\section{Sobre desafios e um caminho entre-línguas}

Muitos são os desafios no ensino de literatura brasileira, tanto no que se refere a pensar em um modo para além do canônico de lecionar literatura, sobretudo, para aprendizes que pertencem a uma minoria linguística, inscritos em um "viver entre-línguas"1. Trata-se de um sujeito que transita, se significa e é significado em distintas línguas, como afirma Maria Tereza Celada (2008), em uma "relação de (des)continuidade entre as línguas"2. Tal relação se dá em um espaço de enunciação, conforme Eduardo Guimarães (2002), um espaço "de funcionamento de línguas, que se dividem, redividem, se misturam, desfazem, transformam por uma disputa incessante"3. Venho trabalhando com a designação "entre-línguas", também sugerida por Rodrigues (2017) e Baalbaki (2014), para pensar como o sujeito surdo é atravessado por uma relação de retesamento entre as línguas de sinais e as línguas nacionais (de modalidade oral e visual pela escrita), em especial, no espaço de enunciação brasileiro, em uma disputa discursiva pelo dizer do surdo e no dizer do surdo.

Neste "viver entre - línguas", em se tratando de aprendizes surdos, a tensão discursiva atravessa também o lugar no qual me encontro inscrita, lugar de professora das disciplinas língua portuguesa e literatura e pesquisadora filiada à análise de discurso pecheutiana: que caminhos seguir para que os aprendizes surdos despertem o interesse e se empoderem para ocupar o lugar de leitor de uma escrita literária em uma língua dita como inatingível? Haveria uma finalidade de ensinar literatura brasileira para surdos que extrapolasse o mero cumprimento de um conteúdo curricular? Como semear que há algo no literário que pode afetar um sujeito que além de surdo, é constituído por outros processos de identificação - ser negro, mulher, periférico, dentre outros? Em se tratando da literatura brasileira, como lidar como uma historicidade que marca a escrita com dizeres em conflito sobre o brasileiro e a língua do/no Brasil, historicidade esta que também assinala um sujeito surdo e brasileiro?

\footnotetext{
${ }^{1}$ Belo título do livro da escritora argentina Sylvia Molloy (2018), que analisa em uma escrita autobiográfica sua experiência com as línguas espanhola, francesa e inglesa.

${ }^{2}$ CELADA, 2008, p.21.

${ }^{3}$ GUIMARÃES, 2002, p.18.
} 
$\mathrm{Na}$ busca por promover uma ruptura com uma rede de dizeres que insiste em reproduzir modelos imaginários (e idealizados) de sujeito surdo, da LIBRAS e da língua portuguesa, buscamos com base na Análise de discurso (PÊCHEUX, ORLANDI) e na História das Ideias Linguísticas (AUROUX, ORLANDI) propor procedimentos para práticas de ensino de literatura brasileira na educação básica. Relatarei neste trabalho um processo que vem sendo desenvolvido com as turmas de $3^{\circ}$ ano do Ensino Médio do Colégio de Aplicação do Instituto Nacional de Educação de Surdos, o CAP-INES, neste caso, com o que é dito como tema Realismo/Naturalismo. No Ensino Médio, mais um desafio se coloca: lidar com um plano de curso (da ordem do documento, do institucionalizar o fazer pedagógico) que preconiza um ensino dos períodos literários, em uma linha(gem) cronológica e por estilos de época e listas de escritores da literatura brasileira, um saber sobre o literário do/no Brasil legitimado como cânone, em um processo discursivo que leva ao encobrimento de outros saberes e de outros modos de ensinar. Conforme Orlandi (1990), o discurso dominante, "o discurso sobre",

[...] consiste em "uma das formas cruciais da institucionalização dos sentidos", alçando determinada posição como legitima, como aquilo que perdura na evidência da memória, em detrimento de outras posições, produzindo um efeito de unidade em relação a determinado saber. Por outro lado, o discurso sobre abriga diferentes discursos de, "e um lugar importante para organizar as diferentes vozes (dos discursos de)" .

Nota-se que essa ordem da repetição sobre o saber literário do/no Brasil predomina nas instituições de educação básica, o que está materializado em livros didáticos, em documentos como os $\mathrm{PCN}$ e a BNCC. Tal funcionamento característico do discurso fundador (ORLANDI, 1993), por sua vez, reverbera na maneira de ensinar, produzindo uma tarefa para o professor de salvaguardar uma tradição por meio de uma forma correta de repetir saberes literários para seus alunos.

$\mathrm{Na}$ outra margem, contudo... há possibilidades de saberes e dizeres outros reclusos pelo discurso dominante virem à luz através de práticas de resistência.

\footnotetext{
${ }^{4}$ ORLANDI, 1990, p. 37.
} 
Com este artigo ${ }^{5}$, almejo mostrar a formulação de uma proposta de construção de saberes literários na partilha com os aprendizes, buscando lidar com o funcionamento do discurso dominante sobre a literatura do/no Brasil, para fazer emergir saberes e dizeres outros. Além disso, tal formulação desestabiliza tanto o lugar do aprendiz como o lugar do professor, no sentido de romper com o imaginário de mera transmissão e recepção de conteúdos. E também traz à tona que é preciso lidar com a disputa e a tensão entre as línguas (LIBRAS e língua portuguesa) e, por sua vez, a relação do sujeito nos lugares de aprendiz e de professor entre si, com as línguas e o objeto de ensino.

É preciso trazer a luz a articulação das noções da Análise de discurso ${ }^{6}$ que alicerçam nossa prática de ensino. Considerando as noções de arquivo ${ }^{7}$ e de trajeto temático ${ }^{8}$, que explicitarei adiante, reunimos, para a aula ${ }^{9}$, dizeres materializados no literário e no artístico do século XIX, tendo como critério a formação de um imaginário de brasileiro ligada a uma discursividade sobre 0 racismo, marcada na literatura e na pintura do século XIX. Um outro critério para a reunião de um arquivo discursivo se refere ao funcionamento do nome de autor enquanto organizador de dizeres ${ }^{10}$, atualizando a memória como um acontecimento discursivo ${ }^{11}$, por comparecer em: lugares de memória ${ }^{12}$, como museus, bibliotecas, arquivos; nomes de ruas, escolas e instituições; estar inscrito em gramáticas e materiais didáticos sobre ensino de literatura; estar materializado em sites de busca e sites institucionais, como da Biblioteca Nacional, Domínio Público, dentre outros. Selecionamos então Aluísio de Azevedo, autor de $O$ mulato $(1881)^{13}$, e o pintor Modesto Brocos, com A redenção de Cam (1895) ${ }^{14}$, que se encontra no Museu Nacional de Belas Artes (RJ). Vale dizer que o trajeto

\footnotetext{
${ }^{5}$ As reflexões do presente trabalho foram apresentadas no IX Seminário de Estudos em Análise de Discurso (SEAD), realizado na UFPE em 2019, sob o título Pelo avesso do bordado: partilhas sobre uma proposta de ensino de literatura para surdos no Ensino Médio do CAP-INES.

${ }^{6}$ Trabalhei mobilizando essas noções em minha tese de doutorado, intitulada Mário de Andrade: um arquivo de dizeres sobre a língua do/no Brasil (UFF-2014), sob orientação de Vanise Medeiros e coorientação de José Luis Jobim.

${ }^{7}$ PÊCHEUX, 2010 [1994], ROMÃO, 2011.

${ }^{8}$ GUILHAUMOU; MALDIDIER ,2010 [1994].

${ }_{9}^{9}$ Aula no sentido de Barthes (2005), centrada no processo de ensino-aprendizagem.

${ }^{10}$ FOUCAULT,1992.

${ }^{11}$ PÊCHEUX, 2008 [1988].

${ }^{12}$ NORA, 1994.

${ }_{11}^{13}$ AZEVEDO, Aluísio. O mulato. Rio de Janeiro: Martin Claret, 2003 [1881].

${ }^{14}$ MODESTO BROCOS. A redenção de Cam, 1895. Óleo sobre tela, 166 X $199 \mathrm{~cm}, \mathrm{RJ}$, MNBA.
} 
temático e os nomes de autor nos levaram a buscar outras materialidades. Assim, buscou-se possibilitar uma fluência de gestos de leitura de diferentes materialidades em lugares de memória ${ }^{15}$ - museus, bibliotecas - e na internet, enquanto espaços de circulação da língua e da memória. A relação entre as artes visuais e a escrita literária nos atravessa de duas maneiras: pode levar à compreensão das condições de produção do discurso literário e de como dizeres se tensionam entre formações discursivas no tecido estético, seguindo caminhos percorridos com os aprendizes para chegar a gestos de leitura; se coaduna com uma proposta de pedagogia visual preconizada pelos estudos sobre a educação de surdos, como instaurado pelos pesquisadores surdos Campello (2008) e Mourão (2018). Mourão, do lugar de professor, pesquisador e surdo, analisa a relação do surdo com a literatura e a designa como "visualiterária", encampando tanto o lugar de autor em língua de sinais como de leitor que sinaliza sentidos pela experiência com sinais literários e também com a palavra escrita. Isto é:

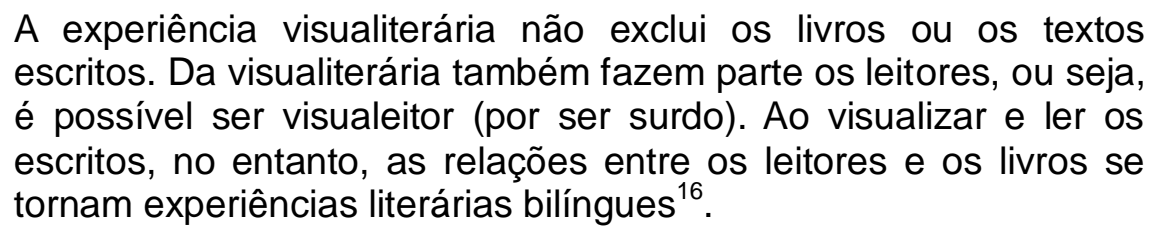

Se pensada pela Análise de discurso, a pedagogia visual compreende um modo de inscrição discursiva do aprendiz surdo através do olhar tanto no lugar de leitor como de autor, materializado na visualidade inerente à língua de sinais e na escrita como representação gráfica tecida em diversas linguagens e línguas, em variados suportes, do papel à tela.

Neste caminho, trabalhei com os aprendizes como um discurso sobre 0 racismo atravessa o imaginário de um Brasil em formação no século XIX e ecoa até hoje, materializado nas pinturas e na literatura do século XIX, mais especificamente nas citadas, e olhando para nossa atualidade, nas redes sociais e em situações vivenciadas pelos próprios surdos, em sua maioria, negras e negros, muitas vezes oriundos da periferia do Rio de Janeiro. No intuito de compreender a formação discursiva dominante em um imaginário nacional para o brasileiro, tomei por base Eni Orlandi (2002). Para tratar da marca do discurso

${ }^{16}$ MOURÃO, 2018, p.185. 
sobre o racismo neste processo, recorri à antropologia, com a intelectual negra Lélia González (1982,1983,1988), que instaura uma rede de saberes sobre o negro e a mulher negra no Brasil e na América, bem como na pesquisadora Lília Schwarcz (2001). Ao mobilizar esta temática com os aprendizes surdos, objetivamos trazer para as aulas de literatura a possibilidade de gestos de leitura que considerem as condições históricas que constituem um discurso artístico, isto é, as condições de produçãa ${ }^{17}$. A leitura das condições de produção é possibilitada pelo funcionamento do nome de autor e sua marca na memória enquanto acontecimento discursivo, atravessando a historicidade e marcando dizeres até nossa contemporaneidade. Ao invés de trabalhar com o conceito de 'contexto' e 'intenção do autor' tão presentes no ensino de literatura, sigo em outra direção, pautada na Análise de discurso, com o objetivo de tornar a aula um espaço de possibilidade de circulação de gestos de leitura. Isto não significa dizer que a prática estaria filiada a um "vale tudo na interpretação", mas que o suporte teórico-metodológico da Análise de discurso pecheutiana configura uma base para a prática de ensino-aprendizagem de literatura. Exporei a seguir as noções que baseiam este trabalho.

\section{Análise de discurso como farol para uma prática de circulação de saberes literários}

Descreverei o procedimento teórico-metodológico que baseia a minha prática de ensino de literatura, pensando na prática como uma possibilidade de formulação e circulação de saberes literários com os aprendizes, por possibilitar gestos de leitura. Para elucidar o suporte da Análise de discurso, faz-se necessário explicitar a relação entre as noções de arquivo, trajeto temático, nome de autor e acontecimento discursivo. Em seguida, mostrarei como a articulação destas noções constroem as atividades com os aprendizes.

Em "Ler o arquivo hoje", Pêcheux formula a noção de arquivo como "campo de documentos pertinentes e disponíveis sobre uma questão"18, salientando que o estudo das práticas históricas de formação de um arquivo requer a análise do

\footnotetext{
${ }^{17}$ Pêcheux, Haroche e Henry (2007 [1971].

${ }^{18}$ PÊCHEUX, 2010 [1994], p. 51.
} 
processo de reunião de documentos e a historicidade do armazenamento e da leitura das informações, sobretudo das relações de poder dizer, isto é, estar no lugar de quem pode gerir, ler e atribuir sentidos a um arquivo.

Desta maneira, é preciso ter em vista também a importância do empoderamento do aprendiz e também do professor no lugar de leitor de um arquivo, de poder emitir gestos de leitura, em uma participação ativa dos saberes que circulam nas aulas. Como afirma Romão (2011), a busca por uma "'voz sem nome' para significar-se ${ }^{19 "}$ leva o sujeito, ao atribuir sentidos ao outro, a significar si mesmo. E é preciso considerar que a experiência visualiterária é constituinte do aprendiz surdo e precisa atravessar o professor de literatura. Para conduzir a leitura do arquivo, mobilizamos as noções de trajeto temático e função-autor.

Guilhamou e Maldidier ${ }^{20}$ formulam a noção de trajeto temático, a partir da concepção de tema, que consiste no interesse pela "emergência dos discursos em circunstâncias determinadas" em relação ao acontecimento discursivo que realiza uma possibilidade de dizer. O trajeto temático "reconstrói os caminhos daquilo que produz o acontecimento na linguagem"21. Ou seja, pelo trajeto temático é possível empreender uma leitura dos dizeres que compõem as condições de produção que determinam o arquivo discursivo.

Segundo Pêcheux, Haroche e Henry, o processo de determinação dos sentidos em uma formação discursiva é fruto das condições de produção, ou seja, "o laço que une as 'significações' de um texto às suas condições sócio-históricas não é meramente secundário, mas constitutivo das próprias significações" ${ }^{22}$ Cabe mostrar então aos aprendizes as condições de produção do discurso artístico e literário no Brasil do século XIX, que emergem a partir da leitura dos materiais de arquivo. Uma discursividade dominante constitui formação do estado nacional brasileiro e, por sua vez, os discursos literário e artístico carregam as marcas deste processo. Conforme Orlandi (2002), "uma formação discursiva positivista"23 instaura pelo dizer da ciência imaginários sobre a sociedade brasileira na virada do século XIX para o XX, por sua vez, do sujeito brasileiro, o que vai afetar a

\footnotetext{
${ }^{19}$ ROMÃO, 2011, p. 105.

${ }^{20}$ GUILHAMOU, MALDIDIER, 2010 [1994], p. 164.

21 idem, p. 165.

22 PÊCHEUX, HAROCHE, HENRY, 2007 [1971], p. 20.

${ }^{23}$ ORLANDI, 2002, p.269.
} 
relação dos sujeitos com a língua. E falar de um sujeito brasileiro na formação do nacional implica necessariamente analisar o imaginário da mestiçagem e da democracia racial. De acordo com Schwarcz:

O certo é que, nas mãos de um discurso de cunho nacionalista, uma série de símbolos vai virando mestiça, assim como uma alentada convivência cultural miscigenada torna-se modelo de igualdade racial. Nesse modelo, pautado numa visão oficial, a desigualdade e a violência do dia-a-dia são como que desprezadas, tudo em nome de uma visão idealizada da 'nossa raça', que nesse momento parece ser suficiente para representar positivamente a nação ${ }^{24}$.

O discurso literário e artístico não passa incólume das marcas da historicidade, por isso, materializa a tensão entre dizeres, o que implica pensar também nos lugares que um autor ocupa - no século XIX, um autor negro que diz sobre o negro poderá estar filiado a uma discursividade contrária ao embranquecimento; um autor branco que diz sobre o negro pode estar identificado ao imaginário da miscigenação. Mas não necessariamente. É preciso considerar, conforme Pêcheux (2009), que o sujeito não tem controle sobre o que diz nem tem a posse do dizer: o sujeito é dividido pela ordem da contradição e as formações discursivas se interpenetram. Isto significa que há vozes materializadas na obra de um autor que fogem a um suposto controle da autoria. Faz-se preciso então compartilhar com os aprendizes os questionamentos de Lélia Gonzalez sobre o mito da democracia racial e a tese de embranquecimento e buscar analisar as tensões no discurso artístico e literário.

[...] o que foi que ocorreu, para que o mito da democracia racial tenha tido tanta aceitação e divulgação? Quais foram os processos que teriam determinado sua construção? Que é que ele oculta, para além do que mostra? Como a mulher negra é situada no seu discurso? $?^{25}$

Tais indagações podem ser mobilizadas pelo funcionamento do nome de autor, como um princípio organizador de discursividades, segundo Foucault (1992), o que é considerado pela Análise de discurso pecheutiana como uma das maneiras de um arquivo discursivo ser formado. Por exemplo, ao buscar por um

\footnotetext{
${ }^{24}$ SCHWARCZ, 2001, p. 31.

${ }^{25}$ GONZALEZ, 1983, p. 225.
} 
nome de autor em sites, catálogos de bibliotecas e arquivos, lombadas de livro, dentre outros, é possível reunir materiais diversos, livros, artigos, fotografias, blogs, inclusive, mobilizando outras autorias que a um outro nome de autor se refere, atravessando diferentes temporalidades e lugares. Desta forma, do nome de um autor é possível formar um arquivo discursivo e o interessante é levar os aprendizes a uma postura ativa, deles mesmos buscarem agregar materiais tendo por mote o nome de autor. Neste sentido, o nome de autor tem profunda relação com o acontecimento discursivo. Explico.

Para Pêcheux, a memória discursiva não é entendida como um monumento fincado no passado, mas sim na fluidez entre o acontecimento e o esquecimento, já que, segundo o autor, a memória é atualizada pelo acontecimento discursivo, compreendido como "ponto de encontro de uma atualidade e uma memória" ${ }^{26}$. Isso quer dizer, por exemplo, que é possível verificar um nome de autor do século XIX em um site de busca como o Google ou nomeando uma escola ou biblioteca. Para um aprendiz surdo que tenha ocupado um lugar de leitor que pode atribuir sentidos, seja pelas mãos, seja pela palavra escrita, ou ambos, ver o nome de autor em uma placa de rua, na entrada de uma escola ou em uma exposição de arte, pode significar pela visualidade da letra uma experiência com o acontecimento em aula, como a preconizada por Barthes (2005). O acontecimento se desdobra então de duas formas, no caso do surdo: na emergência de dizeres da memória discursiva e na experiência no corpo, visualiterária, com o saber. Ambos atravessam o sujeito surdo aprendiz e as duas faces do acontecimento se instauram nas línguas e pelas línguas, mais especificamente, da Libras e da língua portuguesa, em uma tensão entre-línguas pela significação e veiculação dos saberes.

\section{Experiência visualiterária e acontecimento nas aulas de literatura brasileira}

Como se configura o espaço da sala de aula de literatura deste relato? As aulas descritas a seguir foram ministradas para turmas de $3^{\circ}$ ano do Ensino Médio diurno do CAP-INES, em dois tempos de cinquenta minutos semanais. As turmas

\footnotetext{
${ }^{26}$ PÊCHEUX, 2008 [1988]:17.
} 
são formadas por cerca de 8 a 15 aprendizes surdos, dentre os quais há indivíduos com outras necessidades específicas, como TEA, encefalopatia, baixa visão, dentre outras ${ }^{27}$. O espaço físico das aulas na sala ambiente de língua portuguesa e literatura é composto por um computador com acesso à internet (falho, em alguns momentos), projetor de data-show, quadro branco, um armário com livros didáticos e paradidáticos, dicionários, itens de papelaria e alguns materiais organizados pelos professores da equipe de língua portuguesa e literatura. Para o suporte linguístico, sobretudo para professores com pouca fluência em Libras, o colégio conta com Tradutores-intérpretes de Libras e Língua portuguesa (TILSP), importante apoio inclusive para professores ouvintes fluentes em Libras, como é o meu caso, e professores surdos fluentes em Língua portuguesa. É preciso considerar sempre a fluidez das línguas e a tensão em um espaço enunciativo constituído por línguas distintas. Quanto à estrutura digital, o CAP-INES dispõe de um laboratório de informática para atividades com os aprendizes, porém nem sempre os computadores e a internet funcionam. As aulas externas realizadas em lugares de memória foram previamente agendadas no turno da aula e, por vezes, no contraturno, em um tempo médio de duas horas no local e quarenta minutos para o deslocamento. O INES oferece suporte para as saídas: transporte em ônibus próprio; Tradutores-intérpretes de Libras e Língua portuguesa (TILSP); assistentes de alunos, lanche. Ditas as condições operacionais para que o trabalho seja realizado, passo ao esclarecimento de como a base teórica-metodológica da Análise de discurso constituiu um suporte para a minha prática docente.

Vale dizer que ser docente na educação para surdos é um trabalho de investigação para depreender, ou melhor, produzir sentidos entre-línguas: a língua portuguesa escrita é ainda mais opaca para o surdo, que nela pode se inscrever ao mesmo tempo em que é guiado pela LIBRAS - é uma língua portuguesa outra, na tensão entre a recusa e o afeto. Do lugar de professora de língua portuguesa e literatura, ainda que proficiente em Libras, sou também atravessada por uma tensão deste "viver entre-línguas": ao planejar as aulas, preciso além dos recursos visuais buscando pesquisar desde glossários a formas de sinalização

\footnotetext{
${ }^{27}$ Cada sujeito participa diferentemente do processo, sendo respeitadas suas especificidades, por ser tratar de uma proposta pautada na construção dos saberes no acontecimento da aula.
} 
em Libras sobre a temática trabalhada, bem como maneiras de trabalhar a língua portuguesa escrita, lidar com a relação do aprendiz surdo com as línguas e, por sua vez, minha própria experiência entre-línguas, dentre tantos outros desafios que se impõem.

Passo a relatar mais especificamente os procedimentos de trabalho descrito neste artigo. Considerando o trajeto temático e os nomes de autor em questão, levei pinturas, notícias, sequências discursivas de $O$ mulato e classificados nos quais estão encarnados dizeres sobre o negro no século XIX. De modo a efetuar um recorte para a análise, estabelecemos juntos então três vias: 1) gestos de leitura de $O$ Mulato (1881), com a escrita coletiva de um vocabulário; 2) através da busca pelo nome de Modesto Brocos e de Aluísio de Azevedo e de palavras-chave em ferramentas de busca do Google e de sites institucionais como o do MNBA, da Hemeroteca da Biblioteca Nacional, BN digital; no site do Projeto Tráfico de escravos no Brasil, da Biblioteca Nacional ${ }^{28}$, dentre outros, os aprendizes reuniram materiais de arquivo para posterior análise das condições em que foram produzidos; 3) pensando em uma proposta de ensino de literatura através da apropriação de lugares de memória (NORA, 1994), os aprendizes visitaram o Museu Nacional de Belas Artes (MNBA) no Rio de Janeiro e observaram a pintura $A$ redenção de Cam, bem como outras obras do autor, além disso, buscaram informações sobre o autor e as condições de produção em que está inscrito. A análise dos materiais atravessou todo o processo.

Mobilizamos inicialmente O Mulato, de Aluísio de Azevedo, solicitando que os aprendizes destacassem o que haviam compreendido e compartilhassem entre si:

E Raimundo, ali, no desconforto do seu quarto, sentia-se mais só do que nunca; sentia-se estrangeiro na sua própria terra, desprezado e perseguido ao mesmo tempo. "E tudo, por quê?... pensava ele, porque sucedera sua mãe não ser branca!... Mas do que servira então ter-se instruído e educado com tanto esmero? do que servira a sua conduta reta e a inteireza do seu caráter?... Para que se conservou imaculado?... para que diabo tivera ele a pretensão de fazer de si um homem útil e sincero?..." E Raimundo revoltava-se. "Pois, melhores que fossem as suas intenções todos ali o evitavam, porque a sua pobre mãe era preta e fora escrava? Mas que culpa tinha ele em não ser branco e não ter nascido

\footnotetext{
${ }^{28} \mathrm{https}: / /$ bndigital.bn.gov.br/dossies/trafico-de-escravos-no-brasil
} 
livre $?^{29}$

Do lugar de professora, que ministra aulas entre-línguas, vou orientando possibilidades de efeitos de sentidos: que palavras e trechos vocês compreenderam aqui?; quando e onde se inscrevem estes dizeres?; onde este texto pode ter circulado: em jornais, revistas, livros...? vocês percebem essas ideias ainda hoje? Passamos então para uma atividade metalinguística sobre a escrita em língua portuguesa pela Libras, a elaboração de um vocabulário com a turma, produzido com os aprendizes no momento de suas dúvidas e indagações sobre o que está escrito nos trechos do romance. Na reflexão sobre a língua portuguesa escrita, uma língua outra que também pertence ao surdo, a Libras conduz o processo de atribuição de sentidos e de saber sobre as línguas no momento em que os aprendizes efetuam a escrita de cada verbete do vocabulário. Assim, destacamos e listamos as palavras e sintagmas, de forma gráfica para produzir um vocabulário em conjunto, com os efeitos de sentidos que circularam em sala de aula e surgiram deste trecho do romance e de outros dizeres - negro/preto, raça, escravidão/escravo, mestiço, mulato, branco, "não ser branco", livre, puro/pureza, imaculado, estrangeiro... Significamos os verbetes em uma escrita compartilhada conforme o que os aprendizes trocaram entre si e com a docente, daí, emergiram memórias, marcas do já vivido, cicatrizes aferroadas pelo discurso racista em sujeitos surdos e negros, nas mulheres negras e surdas, ... os aprendizes registraram em seus cadernos o vocabulário produzido coletivamente, com o propósito de tomarem para si palavras significadas pela experiência entre-línguas. Com a produção do vocabulário, saberes sobre a escrita foram experienciados em ambas as línguas, possibilitando os aprendizes um arcabouço de conhecimento línguístico para seguirem rumo a leitura de outros materiais.

Para tal atividade, foi preciso, pois, quebrar diversos efeitos de evidência: o que alça a leitura do professor à condição de correta; o que eleva ao efeito de verdade um significado de dicionário ou de outro instrumento linguístico legitimado; o que produz uma facilidade ou dificuldade com o escrito; o que categoriza uma língua e apenas uma língua como 'meio de instrução'.

\footnotetext{
${ }^{29}$ AZEVEDO, 2003, p.134 [1881].
} 
Ao terem experienciado a discursividade sobre o racismo em Libras e na língua portuguesa escrita, com a produção dos verbetes, bem como com outros nomes de autor (pintores, gramáticos, literatos, ativistas, ...) e palavras que emergiram do trajeto temático, fomos aos sites de busca. No século XIX, um classificado de venda de escravos, pinturas de Debret, de Rugendas, o Engenho de mandioca $(1892)^{30}$, um trecho da Grammatica de João Ribeiro sobre a formação do dito "dialecto brasileiro", "um dialecto mestiço, resultante de origens tão complexas" ${ }^{31}$; escritos de Luís Gama, André Rebouças, a pintura de Almeida Júnior... No XXI, notícias sobre injúria racial, comentários de facebook denominando uma jornalista como "macaca"32, uma página na rede sobre a resistência no movimento negro... dizeres sobre o negro que se embatem e são movidos na historicidade.

Para mostrar o que está encoberto, o esboço, o rascunho, aquilo que não se vê e sobre o que não é dito quando nos deparamos com a leitura de um livro ou de uma pintura tidos como prontos, finalizados pelo autor, verificamos as condições em que foram produzidos os materiais: século XIX, de um lado, o auge das teses raciais, como vimos em González e Schwartz, inscritas em uma formação discursiva positivista para produzir efeitos sobre um Brasil e um sujeito brasileiro em emergência, conforme Orlandi (2002); de outro, gestos de resistência praticados por um sujeito negro que luta por sua memória, pela ancestralidade e pode (ou não) ocupar lugares antes exclusivos ao branco europeu, um lugar do letrado, do literato, do médico, do advogado, do engenheiro, um lugar específico na vida letrada que despontava no Brasil.

Assim, como se trata de um gesto de leitura entre-línguas e linguagens, sob o signo do visualiterário, construímos estratégias que partem de uma entrada na língua escrita pelo visual, advindo da própria escrita (o curso da letra no elo com a plasticidade do impresso e do digital) e da Língua Brasileira de Sinais, entrecruzando diferentes materialidades. Como vocês percebem que a palavra negro é significada nesta pintura, neste classificado de venda de escravos, neste

\footnotetext{
${ }^{30}$ MODESTO BROCOS. Engenho de Mandioca, 1892. Óleo sobre tela, $54 \times 75 \mathrm{~cm}$, RJ, MNBA.

${ }^{31}$ RIBEIRO, João. Grammatica Portugueza. (3oano) Rio de Janeiro, Livraria clássica de Alves \& Comp. : 1888, 2.ed, p.309-310.

${ }^{32}$ Analisamos, por exemplo, comentários referentes à Jornalista Maju Coutinho ao assumir a apresentação no Jornal Nacional da Rede Globo de televisão.
} 
trecho do romance, nesta definição da gramática, neste jornal abolicionista? Vamos buscar alguma notícia atual a partir da palavra racismo? Distinguimos eixos de formações imaginárias, considerando as possibilidades de cruzamentos de dizeres no trajeto temático sobre o racismo no século XIX, para chegarmos às tensões discursivas, procurando sempre pensar nos ecos presentes na língua ainda hoje.

Nas redes, os aprendizes navegam pelo digital, buscando pelo nome de autor e por palavras-chave pistas e materiais de arquivo, seguindo o fio entre os links, levando a avanços e recuos, a salvar e a perder(-se) nos caminhos entre sites institucionais e pessoais, o que incita a uma reflexão sobre o que é legítimo e o que é legitimado como saber sobre o literário, sobre os efeitos de verdade produzidos pela própria tessitura da internet. Uma reflexão que é atravessada pelo estar entre-línguas, por buscar atribuir sentidos em Libras e em língua portuguesa escrita, em um processo de reflexão metalinguística, no caso, pensando sobre como o racismo pode significar e ganhar forma material na escrita em língua portuguesa e na sinalização em Libras. Por exemplo, uma busca no google pelo nome de autor impele a uma navegação entre links e sites fazendo emergir documentos e manuscritos do século XIX com um suporte duplo, ao mesmo tempo o do papel amarelado com as marcas da ação do tempo e o do instante capturado que permanece pelo digital. Para empreender tal busca, é necessário que o aprendiz produza gestos de leitura e de escrita, acionando saberes sobre as línguas no momento da busca - da grafia da palavra ao lugar onde empregá-la em uma ferramenta de busca e a análise do que foi (e do que não foi) encontrado, trata-se de uma construção de saber sobre as línguas na atuação do aprendiz no processo pedagógico. As atividades metalinguísticas são conduzidas em elo com o processo de significação entre a Libras e a língua portuguesa, é necessário, por exemplo, trabalhar com atividades de memorização, relacionando a sinalização com a datilologia (digitação manual da palavra), a escrita à lápis e digitada no computador.

Dessa maneira, ao acessar sites institucionais, os aprendizes são levados pelo funcionamento do nome de autor, que se encontra com o do trajeto temático a perseguir, por retornarem nos catálogos eletrônicos, podendo levar (ou não 
levar) a materiais de arquivo como os disponíveis na Hemeroteca digital, no Projeto Tráfico de Escravos no Brasil, ambos da Biblioteca Nacional, ou na Academia Brasileira de Letras. Os aprendizes salvaram em pastas réplicas de pinturas, folhetos, notícias, em um trabalho de formação de arquivo, configurando uma prática pedagógica possibilitada pelo encontro entre atualidade e memória, conforme Pêcheux (2008 [1988]).

Se a rede possibilita extrapolar virtualmente os muros da escola, ainda assim é necessário que o corpo experiencie a saída, ocupe a rua e os lugares que salvaguardam as tensões da memória, como espaços museais, bibliotecas, galerias, dentre outros. Seguimos para o Museu Nacional de Belas Artes, nos detendo à Redenção de Cam (1895), de Modesto Brocos:

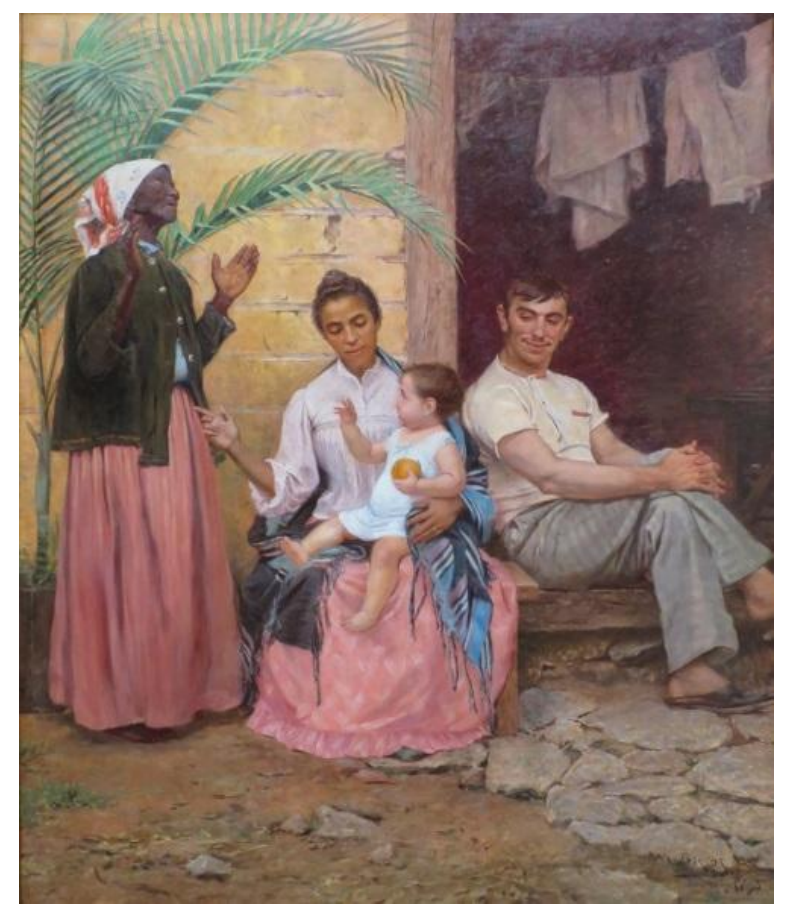

Figura 1: MODESTO BROCOS. A redenção de Cam.

Óleo sobre tela, 166 X 199 cm, RJ, MNBA, 1895.

Sobrancelhas franzidas, sinais em Libras que fazem emergir um confronto de dizeres. A pintura, com a qual Brocos logrou uma medalha de ouro na Exposição Geral de Belas Artes em 1895, foi utilizada para ilustrar a tese de João Batista de Lacerda, no / Congresso Mundial das Raças em 191133, estudo eugenista que consistia em que o Brasil seria formado por um povo ${ }^{33}$ LOTIERZO; SCHWARZ, 2013. 
embranquecido em três gerações, um dizer cientificista sob a guarda da formação discursiva positivista, como já dito, a formação dominante na constituição do estado nacional brasileiro. Almejando um dizer na ruptura desta formação, que ainda hoje se presentifica, seguimos com as instigações de Lélia González, sobretudo para pensar, a partir da representação na pintura de Brocos, no lugar da mulher negra no Brasil:

A diferença (se é que existiu), em termos de Brasil, estava no fato de que os casamentos inter-raciais" nada mais foram do que o resultado da violentação de mulheres negras por parte da minoria branca dominante (senhores de engenhos, traficantes de escravos etc.). Este fato daria origem, na década de trinta, à criação do mito que até os dias de hoje afirma que o Brasil é uma democracia racial. Gilberto Freyre, o famoso historiador e sociólogo, é seu principal articulador, com sua teoria do lusotropicalismo. O efeito maior do mito é a crença de que o racismo inexiste em nosso País graças ao processo de miscigenação ${ }^{34}$.

$\mathrm{Na}$ oficina, pergunto de um lugar autorizado a saber sobre a pintura: vocês acham que essa pintura não deveria ser mais exposta no museu, por ser uma pintura racista, que apoia a tese de embranquecimento? Replicam os aprendizes, estranhando evidências: parece ter sido esta a intenção do pintor ...mas há algo estranho na pintura, ela está dividida entre a luz e o fusco, o homem branco está em um fundo escuro; as mulheres negras em um fundo claro, pintadas como se fossem santificadas (e apontam para outras pinturas sacras, onde o negro não figura, e para os ramos e as posturas das mulheres na pintura de Brocos, a comparar as imagens de obras sob o sinal do cânone, do academicismo). E pintar uma mulher negra no imaginário de santidade cristã também não é uma forma de embranquecê-la? E não dizer sobre a tese de embranquecimento é uma forma de combatê-lo ou de fortalecê-lo? A avó negra e escrava não resiste no neto, mesmo de pele branca? Assim, emergem no dizer entre-línguas dos aprendizes surdos os materiais que lemos. Em O Mulato, os aprendizes verificaram que era preciso narrar: embora o personagem Raimundo tenha alçado um lugar no ambiente letrado pelo embranquecimento, a marca da escravidão latejava, o racismo imperava e ainda impera em tantos Raimundos. Retornam os gestos para a pesquisa: os nomes de autor e outras perguntas que conduzem a entrada no

${ }^{34}$ GONZALEZ, 1982, p.89. 
trajeto temático fluem sinalizados pela Libras e procuram pistas na pintura e na escrita (anotações, nas legendas dos quadros, nos celulares)... Como o corpo da negra marca a pintura de Brocos sendo representado como uma madona? Como o corpo de Raimundo carrega a ancestralidade e desestabiliza o status por ocupar um lugar de advogado, ao mesmo tempo em que é dito como um negro embranquecido, um mulato? Há algo que marca pela tensão a pintura e o romance, que escapa tanto a um suposto controle e intencionalidade do pintor e do escritor como de uma dita leitura unilateral, algo fala na pintura e no romance retomando uma ancestralidade de resistência negra pelo dizer dos aprendizes surdos. E é justamente o gesto de ousar perguntar se há algo de estranho no dizer aparentemente estabilizado que pode ser considerado uma avaliação.

Logo, a avaliação atravessa todo o processo, não se restringindo a uma prova ou a um trabalho e foram vários os momentos nos quais um olhar sobressaltado, de desconfiança para o dito, levaram ao questionamento, à pergunta, a verificar as tensões no discurso sobre o racismo. Ainda assim, por se tratar de Ensino Médio e pela importância dos aprendizes terem a experiência com o modelo de questões bilíngues do Enem, houve um momento de 'prova' seguindo a dinâmica do exame, elaboradas e gravadas em Libras por mim com apoio da equipe de intérpretes e técnica do estúdio Flausino Gama Filho do INES $^{35}$. Os aprendizes experienciaram todo o ritual, e foram orientados a lidar com a prova impressa, cartão resposta e os vídeos em Libras. ${ }^{36}$ Cabe do lugar de professor perceber então os efeitos da experiência visualiterária em cada aprendiz para significar a avaliação como algo que implica olhar para os processos individuais e coletivos de transformação pelo saber através da experiência.

\section{Uma experiência visualiterária com aprendizes surdos}

Entre lugares de memória, livros, a rede e um caminho outro para o espaço escolar, discursividades circulam e possibilitam a emergência do acontecimento

\footnotetext{
${ }^{35}$ As etapas deste processo serão relatadas em um artigo futuro. Infelizmente, é sabido que a maioria dos colegas docentes não dispõe deste aparato técnico.

${ }^{36}$ Vale destacar também o projeto do Simuladinho no INES, coordenado pelos professores André Cordeiro e Danielle Lins.
} 
na aula, levando a gestos de leituras, dos lugares de professora e de aprendiz surdo, sobre dizeres que disputam sentidos sobre o negro e o racismo no século XIX e retornam no XXI. É um ato também o de inscrever o corpo do sujeito surdo em espaços museais e em bibliotecas, um corpo que é também suporte de uma língua outra para um ouvinte, a LIBRAS, um corpo que vem da periferia, um corpo surdo que também pode ser negro, de mulher, de jovem, de idoso, feminino, masculino, gay, trans etc. Um corpo que balança as estruturas por onde transita pelo movimento da LIBRAS, constituído de um visualiterário, indagando sobre sentidos estabilizados, sendo capturado por gestos de resistência do negro no curso de uma história que também diz de si. A finalidade é, portanto, possibilitar o acontecimento nas aulas de literatura, em uma experiência que atravessa 0 sujeito no lugar de aprendiz e no lugar do professor relacionando um processo de empoderamento sobre saberes literários e linguísticos ao reconhecimento do próprio lugar e do outro na historicidade do discurso.

\section{Referências}

AZEVEDO, Aluísio. O mulato. Rio de Janeiro: Martin Claret, 2003 [1881].

BAALBAKI, A. C. F.; CALDAS, Beatriz. Como a língua portuguesa se organiza em um espaço de enunciação ampliado. In: Angela Baalbaki; Beatriz Caldas. (Org.). Instrumentos linguísticos: usos e atualizações. 1ed. Araruama: Editora Cartolina, 2014 , v. 1, p. $75-102$.

BARTHES, Roland. Aula. São Paulo, Cultrix, 2005

BUSCÁCIO, Lívia Letícia Belmiro. Mário de Andrade, um arquivo de saberes sobre a língua do/no Brasil. (Tese de doutorado). Programa de Pós-graduação em Estudos da Linguagem do Instituto de Letras da UFF. Niterói, 2014.

CAMPELLO, Ana Regina de Sousa. Aspectos da visualidade na educação de surdos. Tese de doutorado. Programa de Pós-Graduação de Educação da Universidade Federal de Santa Catarina. Florianópolis, 2008.

CELADA, MT. Língua materna/língua estrangeira: um equívoco que provoca a interpretação. In: Análise do discurso no Brasil: mapeando conceitos, confrontando limites. São Carlos: Claraluz; 2007.

GONZALEZ, Lélia. Racismo e sexismo na Cultura Brasileira. In: SILVA, L. A. Movimentos sociais urbanos, minorias étnicas e outros estudos. Brasília: ANPOCS, Cap. 3, 1983. (Ciências Sociais Hoje, 2) 
A Mulher Negra na Sociedade Brasileira (Uma abordagem políticoeconômic[a]). In: MADEL, Luz. (org.). O lugar da Mulher (Estudos sobre a condição feminina na sociedade atual)". Rio de Janeiro: Graal, V.1, 1982, (Coleção Tendências).

GUILHAUMOU, J., MALDIDIER, D. Efeitos do arquivo. A análise do discurso no lado da história. In: ORLANDI, E.(org.) Gestos de Leitura. Campinas: UNICAMP, 2010 [1994]

LOTIERZO, T.; SCHWARCZ, L. M. . Raça, gênero e projeto branqueador : A redenção de Cam, de Modesto Brocos. Artelogie (Online), v. 1, p. 1-25, 2013. Disponível em: http://cral.in2p3.fr/artelogie/spip.php?article254

MODESTO BROCOS. A redenção de Cam. Óleo sobre tela, 166 X $199 \mathrm{~cm}, \mathrm{RJ}$, MNBA, 1895.

MOLLOY, Sylvia. Viver entre línguas. Belo Horizonte: Relicário, 2018

NORA, Pierre. "Entre mémoire et histoire: la problématique des lieux." IN: Les lieux de mémoire. Paris: Gallimard, 1984. Vol 1. Pp. 7 a 15 (Tradução na Revista Projeto História. No 10 História \& Cultura. São Paulo, PUC-SP - Programa de Pós-Graduação em História, dezembro de 1993. Pp. 7 a 26.)

MOURÃO, Cláudio Henrique. Literatura surda: experiência das mãos literárias.Tese de doutorado. Programa de Pós-Graduação em Educação, da Universidade Federal do Rio Grande do Sul (UFRGS). Porto Alegre, 2018.

ORLANDI, Eni (org). Língua e conhecimento linguístico. Campinas: Pontes, 2002.

"Segmentar ou recortar". In Linguística: questões e controvérsias, publicação do Curso de Letras do Centro de Ciências Humanas e Letras das Faculdades Integradas de Uberaba, Série Estudos - 10, 1984, pp. 9-26.

PÊCHEUX, Michel, HAROCHE, Claudine; HENRY, Paul. A Semântica e o Corte Saussuriano: língua, linguagem, discurso. In: BARONAS, R.L. Análise do Discurso: apontamentos para uma história da noção-conceito de formação discursiva. São Carlos/SP: Pedro e João editores, 2007 [1971].

PÊCHEUX, Michel. Semântica e discurso; uma crítica à afirmação do óbvio. Campinas: Ed. da UNICAMP, 2009 [1988-1 1ㄹ $^{\text {Ed.] }}$

[1988].

. O discurso: estrutura ou acontecimento? Campinas: Pontes, 2008

- Ler o arquivo hoje. In: ORLANDI, Eni P. (org). Gestos de leitura. Campinas: Editora da Unicamp, 2011. [1994 - 1.ed.]

RIBEIRO, João. Grammatica Portugueza. (3oano) Rio de Janeiro, Livraria clássica de Alves \& Comp. : 1888, 2. ed. 
RODRIGUES, Verônica O. L. "A inclusão é uma confusão": Surdos na travessia entre-línguas e práticas escolares, Mestrado em Estudos de Linguagem pelo Programa de Pós-graduação do Instituto de Letras da Universidade Federal Fluminense. Niterói, 2017

SCHWARCZ, Lília Moritz. Racismo no Brasil. São Paulo: Publifolha, 2001.

SCHERER, Amanda. O nome da língua, um modo de fazer. Gragoatá, Niterói, v.24, n. 48, p. 14-24, jan.-abr. 2019

Lívia Letícia Belmiro Buscácio é Doutora em Estudos da Linguagem pela UFF (2014) e professora de língua portuguesa e literatura do Instituto Nacional de Educação de Surdos, desde 2007. Leciona para turmas de educação básica e é professora permanente no Mestrado em Educação bilíngue para surdos, além de atuar na formação de professores da educação básica por meio de assessorias promovidas pelo INES para todo o Brasil. É pesquisadora vinculada ao Grupo Arquivos de língua, sob a coordenação de Vanise Gomes de Medeiros (UFF), que agrega 19 instituições nacionais e internacionais. Encontra-se em estágio de Pósdoutorado em Linguística pelo Programa de Pós-graduação em Letras da UERJ, sob a supervisão de Ângela Corrêa dos Santos Baalbaki.

Recebido em 08 de abril de 2020. Aprovado em 30 de abril de 2020. 